4 Scrimshaw, N S, Taylor, C E, and Gordon, J E, Interactions of Nutrition and Infection, WHO Monograph No 57. Geneva, World Health Organisation, 1968.

${ }^{5}$ Heatley, R V, Williams, R H P, and Lewis, M H, Postgraduate Medical fournal, 1979, 55, 541.

B Moghissi, K, et al, British Fournal of Surgery, 1977, 64, 125.

${ }^{7}$ Murray, M J, et al, British Medical fournal, 1978, 2, 1113.

${ }^{8}$ Fielding, L P, Stewart-Brown, S, and Dudley, H A F, Lancet, 1978, 2, 778.

\section{The undiscovered country}

For believers and unbelievers alike, man's survival in some form after death is no problem. The believer has his unshakable certainties-diversified in a variety of religions. The unbeliever's certainty rests on the lack of any scientifically acceptable evidence that activity of the human mind survives death of the brain.

So doubts about the possibility of some form of life after death remain to puzzle only the sceptics and the agnostics. These, particularly if trained in the ways of science, are far from happy with "evidence" from spiritualism and mediums and from accounts of ghosts and apparitions. (Lack of confidence in these paranormal experiences does not necessarily throw doubt on the rather better evidence of equally inexplicable phenomena such as thought transference and extrasensory perception, but psychic interchanges between living people are irrelevant to the question of survival.) Thus the parascientific areas are not yet entirely respectable; for example, Dr Eugene Brody felt obliged to defend his editorial decision in 1977 to devote a whole issue of his journal ${ }^{1}$ to the paranormal, reincarnation, and the evidence of man's survival after death. One of his contributors on that occasion-Ian Stevenson-has recently, with a colleague, ${ }^{2}$ examined a narrower issue. What conclusions, if any, can justifiably be drawn from near-death experiences?

The material they surveyed includes accounts from people falling in climbing accidents who expected to die but escaped, ${ }^{3}$ experiences recorded from people after cardiac arrest ${ }^{4-6}$ and other near-fatal illnesses, ${ }^{3} 78$ and the stories of the rare people who have survived suicidal jumps ${ }^{9}$ from the Golden Gate bridge, San Francisco (the world's favourite starting-point for a suicidal leap, with 535 suicides since it opened in 1937). Stevenson and Greyson ${ }^{2}$ were able to identify some common features, which agreed with the rather sparse reports of others who have studied similar material.

Most of these survivors commented on the increased speed of thought that they experienced and on the slowing and expansion of time. They agreed, too, on an absence of fear and on a calmness and tranquillity of mind. Many gave accounts of panoramic memory and a review of previous life-the traditional experience of the drowning man. The exceptions were survivors from the Golden Gate bridge, none of whom had experienced any form of panoramic memory. The absence of this sensation in these would-be suicides may have been connected with the lack of unexpectedness, so characteristic of both the mountaineering and the cardiac-arrest groups. Moreover, several of those who jumped were psychotic or at least mentally abnormal.

Another experience frequently mentioned was autoscopyseeing oneself lying or standing apart from oneself as a spectator. Some writers on autoscopy compare it to the doppelgänger experience, ${ }^{1011}$ which is seen by one author as a denial of death. ${ }^{12}$ Hackett $e t a l^{5}$ reported denial of death but not autoscopy in 20 out of 50 survivors of coronary infarction. Depersonalisation-feeling the self to be unreal-is another frequent consequence of a near-death experience. ${ }^{3} 7$ This is difficult to understand, because the feeling-tone in the classic description of depersonalisation ${ }^{13}$ is most unpleasant, whereas descriptions of near-death emphasise sensations of calmness and serenity. Most of those who have been near death have also described some kind of mystical or transcendental experience-heavenly colours, visions, a conviction of having "entered an unearthly realm," or an impression of rebirth.

The striking agreement in the reports from people in different countries and cultures and in different decades encourages the belief that valid conclusions could be drawn from them; but Stevenson and Greyson ${ }^{2}$ are nevertheless right in advocating caution. Suggestion on the part of the interviewer (whether enthusiastic or sceptical), subtle communication from other survivors, and published and broadcast accounts of others' experiences may all play a part in exaggerating any apparent conformity in survivors' accounts. More important, these accounts are-by definition-neardeath experiences and depend, so far as we know, on a functioning and not a dead brain. Noyes ${ }^{14}$ reminds us that "no one has returned from the dead and given an account of his experiences." Death remains, in Hamlet's words, "The undiscover'd country from whose bourn/No traveller returns...." The near-dead are not dead; and the dead, whether surviving in some form or not, can be left to thanatology and eschatology.

${ }^{1}$ Brody, E B, Fournal of Nervous and Mental Disease, 1977, 165, 151.

2 Stevenson, I, and Greyson, B, Fournal of the American Medical Association, 1979, 242, 265.

${ }^{3}$ Noyes, R, and Kletti, R, Psychiatry, 1976, 39, 19.

4 Druss, R G, and Kornfeld, D S, Fournal of the American Medical Association, 1967, 201, 291.

${ }^{5}$ Hackett, T P, Cassem, N H, and Wishnie, H A, New England fournal of Medicine, 1968, 279, 1365.

${ }^{6}$ Dobson, M, et al, British Medical fournal, 1971, 3, 207.

${ }^{7}$ Noyes, R, et al, fournal of Nervous and Mental Disease, 1977, 164, 401.

${ }^{8}$ Sabom, M B, and Kreutziger, S, fournal of the Florida Medical Association, 1977, 64, 648.

${ }^{9}$ Rosen, D H, Western fournal of Medicine, 1975, 122, 289.

${ }^{9}$ Rosen, D H, Western fournal of Medicine, 1975, 122, 289.
${ }^{10}$ Lukianowicz, N, Archives of Neurology and Psychiatry, 1958, 80, 199.

11 Trethowan, W H, in Current Themes in Psychiatry 2, ed R N Gaind and B L Hudson, p 317. London, Macmillan, 1979.

12 Ehrenwald, J, fournal of Nervous and Mental Disease, 1974, 159, 227.

13 Ackner, B, Fournal of Mental Science, 1954, 100, 838.

14 Noyes, R, Psychiatry, 1972, 25, 174.

\section{Palindromic rheumatism}

Hippocrates has been quoted as a precedent ${ }^{1}$ for the use of "palindromic" to signify a recurring condition. In theory it could be applied, say, to angioneurotic oedema or proctalgia fugax. In medical practice nowadays the term is practically confined to "palindromic rheumatism," a rare disorder with a relatively short history.

First described by Hench and Rosenberg in $1944,{ }^{2}$ palindromic rheumatism is characterised by repeated attacks of pain in or near joints and lasting from hours to days. The bouts subside completely without residual disability. Men and women are equalıy susceptible. The hands and wrists seem to be especially frequently and severely affected; and pain, redness, and swelling may be striking. Inflammation of 